\title{
The Athlete Sleep Quality in the Training Center
}

\author{
Ni Nyoman Mestri Agustini*, Ketut Budaya Astra \\ Faculty of Sport and Health \\ Universitas Pendidikan Ganesha \\ Bali, Indonesia \\ *nyoman_mestri@yahoo.com
}

\begin{abstract}
The training centre condition will change the athlete's training intensity, duration, and responsibility. Hormonal imbalances can cause a bad sleep quality. Sleep quality is very important to keep the fit condition of the athletes, so that their performance will be maximum in the match, especially during in the training centre. This study was aimed at determining the sleep quality of athletes in the training centre. This research was conducted in the athlete training centre of Kota Madya Denpasar on the athletics, badminton, and bicycle racing athletes who underwent training concentrations for the 2017 PORPROV (Bali Province Sport Games) preparation. The study used quantitative descriptive design. The assessment of sleep quality used PSQI (The Pittsburgh Sleep Quality Index) questionnaire. Based on the results of the study, it found that the sleep quality of each sports was different. In general, $50 \%$ of the athletes had a good sleep quality and $50 \%$ of the athletes had a bad sleep quality. Based on the type of sports, $40 \%$ of athletics athletes had a good sleep quality, while $60 \%$ of them had a bad sleep quality. 55\% of bicycle racing athletes had a good sleep quality and $45 \%$ of them had a bad sleep quality. 64\% of badminton athletes had a good sleep quality and $36 \%$ had a bad sleep quality. It concludes that half of the athletes who underwent the training concentration had sleep disorders with different percentages for each sport.
\end{abstract}

\section{Keywords: athlete, training center, sleep quality}

\section{INTRODUCTION}

The performance condition of an athlete is determined by the optimal balance of training and rest. The training that an athlete undergoes is one form of physical stressor. The training centre essentially provides physical pressure regularly, systematically and continuously so that it can improve the physical ability of the athletes. When undergoing training centre, the athletes can experience training and recovery imbalances. This condition can take place continuously so that it has an impact on physical stress conditions for the athletes. An imbalance of Hypothalamic-Pituitary-Adrenal cortex axis (HPA axis) is due to prolonged stress condition [1]. Furthermore, it will cause changes in the sleeping cycle to sleeping disorder [2,3] which will result in repeated stress.

Athletes in the training centre are one group of people who often experience sleeping disorder. The research conducted before by Juliff LE et.al stated, more than half of the athletes experienced worse than usual sleep during the last 12 months of exercise [4]. Another study by LeBlanc also showed that there was sleeping disorder on the athletes during the match preparation [5]. The research on the athletes' cortisol level found an increase on cortisol level for the subjects who underwent heavy intensity training within 8 weeks significantly [6]. A study on 15-25 years samples undergoing 4 weeks of aerobic exercise with medium intensity, found significant increase on the cortisol hormone [7].

Data collection on the sleep quality of athletes is important to prepare athletes having their best condition at the time of the match. The training centre condition of the athletes will change the training intensity, duration and responsibility. This study aims to determine the sleep quality of the athletes in the training centre.

\section{METHOD}

This study used quantitative descriptive observational method to determine the sleep quality of the athletes in the training centre. Both subject characteristics and sleep quality examination were carried out at the athletes training centre of Kota Madya Denpasar starting from June to November 2017. The sample used in this study were all athletes of Kota Madya Denpasar of athletics, badminton and bicycle racing athletes who underwent training concentration in preparation for 2017 PORPROV.

The study was carried out in the athlete training centre that had lasted for 1 month. Of the total athletics athletes, bicycle racing and badminton, there were 64 athletes who met the criteria and were willing to become research samples. Data collection characteristics were carried out first. Sleep quality examination was carried out using PSQI questionnaire with 7 components examination, namely latency, duration, quality, efficiency of sleep habits, sleep disorder, the use of sleeping pills, and the disruption of body function during the day [8]. Sleep quality assessment is good if the PSQI score is $\leq 5$ and sleep quality is bad if the PSQI score is> 5. The results of the study are presented in quantitative descriptive regarding the sleep quality of the athletes in the training centre.

\section{RESULTS AND DISCUSSIONS}

Based on the conducted research, the results of the subject characteristics are as follows. (See table I)

Athletes of athletic sports were $46.9 \%$, bicycle racing $31.2 \%$ and badminton $21.9 \%$ with median age of 16.5 years. The percentage of sex is $57.8 \%$ male and $42.2 \%$ female. 
TABLE I. The CHARACTERISTICS OF RESEARCH SubJeCtS

\begin{tabular}{|l|c|c|}
\hline \multicolumn{1}{|c|}{ Variables } & N & \% \\
\hline Sports & 30 & 46,9 \\
Athletics & 20 & 31,2 \\
Bicycle Racing & 14 & 21,9 \\
Badminton & 37 & \\
\hline Sex & 27 & 57,8 \\
Male & $16,50(13-31)$ & 42,2 \\
Female & & \\
\hline Age (Years) & & \\
Median (min-max) & & \\
\hline
\end{tabular}

Based on the examination of sleep quality using the PSQI questionnaire, by distinguishing good sleep quality with PSQI value $\leq 5$ and bad sleep quality with PSQI value $>5$, the following results were obtained.

TABLE II. SLEEP QuALITY OF THE ATHLETES

\begin{tabular}{|c|c|c|}
\hline Sports & $\begin{array}{c}\text { Good sleeping quality } \\
(\mathbf{\%})\end{array}$ & $\begin{array}{c}\text { Bad sleeping quality } \\
(\boldsymbol{\%})\end{array}$ \\
\hline Athletic & $12(40)$ & $18(60)$ \\
\hline Bicycle racing & $11(55)$ & $9(45)$ \\
\hline Badminton & $9(64)$ & $5(36)$ \\
\hline Total & $32(50)$ & $32(50)$ \\
\hline
\end{tabular}

Based on the table 2 above, it can be seen that in general, the percentage of athletes who have good and bad sleep quality is equal. But there are differences for each sports. In athletics, there are more athletes who have bad sleep quality $(60 \%)$. In the sports of bicycle racing, the percentage of good and bad sleep quality is almost equal. Whereas in badminton, there are more athletes who have good sleep quality (64\%).

TABLE III. THE CHARACTERISTICS OF RESEARCH SUBJECTS BASED ON SLEEP QUALITY

\begin{tabular}{|l|c|c|c|}
\hline Variables & Bad sleeping quality & $\begin{array}{c}\text { Good sleeping } \\
\text { quality }\end{array}$ & Total \\
\hline Sex & & $20(54.1 \%)$ & $100 \%$ \\
\hline Male & $17(45.9 \%)$ & $12(44.5 \%)$ & $100 \%$ \\
\hline Female & $15(55.5 \%)$ & $16,00(14-21)$ & \\
\hline $\begin{array}{l}\text { Age (Years) } \\
\text { Median } \\
\text { (min-max) }\end{array}$ & $17,00(13-31)$ & \\
\hline
\end{tabular}

Based on the table 3 above, the percentage of female athletes who have good sleep quality is higher than male athletes. Judging from age, the median age of athletes who have good and bad sleeping quality is almost the same, namely 17 years and 16 years old.

Based on the results of the study, there were more percentages of female athletes who had bad sleeping quality during training centre (55.5\% of the total female athletes), compared to male athletes $(45.9 \%$ of the total male athletes). The results of this study similar to previous studies which found that sleep efficacy of male athletes were worse than women [9]. Other research also mentions that the ratio of male and female adolescents who have bad sleep quality is greater in male athletes, which is 1.02: 1 [10]. The bad sleep quality of women compared to men is related to biological factors of hormonal changes [11].

The age aspect of sample, median age is 16.5 years. The more athletes with ages $\geq 16.5$ years old the more likely to experience bad sleep quality (53.1\%) compared to age $<16.5$ years old $(46.9 \%)$. The results of this study are similar to previous studies which found that athletes with greater age, i.e. 15 to 19 years old, had worse sleep quality than those aged 10 to 14 years old, namely 1.26: 1 [10]. The explanation that can be given is that in older age groups, it is associated with emotional modulation, the lack of sleep is related to daily stress and the aspects of social relations [10].

In these three sports, there is difference in the percentage of bad sleep quality events. Athletes who experience bad sleep quality from athletic are as much as $56.2 \%$, bicycle racing are as much as $28.1 \%$ and badminton are as much as $15.6 \%$. These three sports are the sport that competed in Bali 2017 PORPROV and included in sports that have equal level of training responsibility. The energy needs of these three sports are almost the same [12].

Based on the results of sleep quality examination, it was found that half of the samples $(50 \%)$ of athletes who took part in training centre had bad sleep quality. Condition like this is related to the athlete condition changes. The results of this study are similar to the previous studies on sleep in athletes before the game, found that athletes with bad sleep quality are more than fifty percent. Athletes during training centre experience excessive physical stress in the preparation for the match [13]. Excessive physical stress will affect the neuroendocrine system. Hypothalamic-Pituitary-Adrenal Axis will be disrupted by physical stress causing an increase in cortisol hormone. Where this increase in cortisol causes an awake response and disrupts the sleep cycle and sleep quality becomes bad [14-16]. Research on sleep efficiency with increased cardiovascular and cortisol stress, leads to bad sleep quality efficiency [17]. High cortisol levels will affect the central nervous system, which changes electrical waves in the limbic and hippocampus systems, affecting the sleeping cycle, causing cortisol awakening responses (CAR). Increased wakefulness, increased EEG frequency in the sleeping phase and decreased short sleep waves, sleep will become intermittent, reduced slow waves, shortened sleep and insomnia $[3,18]$.

Each sport has different percentage of sleep quality. In athletics, most athletes $(60 \%)$ have bad sleep quality. In contrast to bicycle racing, the percentage of athletes who have bad sleep quality is less than half (45\%). Likewise, in badminton, were $36 \%$. The difference in the percentage of sleeping quality for each sport is influenced by the activities carried out during training in each sport. Training centre activities in each sport will give excessive physical stress to athletes, resulting in hormonal changes in the body. The condition causes the athletes sleep quality to be disrupted $[14,16,17]$. 
[8] D.J. Buysse, C.F. Reynolds, T.H. Monk, S.R. Berman, and D.J. Kupfer, "The Pittsburgh Sleep Quality Index: a new instrument for psychiatric practice and research," Psychiatry Res, May, vol. 28(2), pp. 193-213, 1989.

Based on the results of the study, it can be concluded that half of the athletes who underwent training concentration had bad sleeping quality, with percentage difference seen from the aspects of age, sex and type of sports.

\section{ACKNOWLEDGMENT}

The authors would like to thank Nuartha AABN, Laksmidewi AAA Putri and Eka Widyadharma for their guidance and assistance throughout this process on this study. FPOK UPI team for guidance on articles writing process.

\section{REFERENCES}

[1] M. Andriani and S. Subhan, "Perancangan Peralatan secara Ergonomi Guyton and Hall, Buku Ajar Fisiologi Kedokteran,” Jakarta: EGC, 1996.

[2] Kandhalu Preethi, "Effects of Cortisol on Physical and Psychological Aspects of The Body And Effective Ways By Which One Can Reduce Stress," Berkeley Scientific Journal 2013 Volume 18, Issue 1, 2013.

[3] Hudson Tori and Bush Bradley, "The Role of Cortisol in Sleep," Natural Medicine Journal, vol. 2(6), June 2010.

[4] L.E. Juliff, L. Shona, and J. Jeremiah, "Understanding sleep disturbance in athletes prior to important competitions," J Sci Med Sport, 2014.

[5] M. LeBlanc, M. Chantal, S. Josée, I, Hans, B. Lucie, and M. Charles, "Incidence and Risk Factors of Insomnia in a Population-Based Sample,” SLEEP 2009, vol. 32(8), pp. 1027-1037, 2009.

[6] M. Hamid, M. Azizi, and M. Hiwa, "Effect of 8 Weeks Low and High Intensity Resistance Training on Leukocyte Count, Igg, Cortisol and Lactate Concentration in Untrained Men," World Applied Sciences Journal, vol. 16 (7), pp. 949-954, 2012.

[7] A. Alghadir, S. Gabr, and A. Farag, "The effects of four weeks aerobic training on saliva cortisol and testosterone in young healthy persons," J. Phys. Ther. Sci, vol. 27, pp. 2029-2033, 2015.
[9] L. Jonathan, G. Mark, P. Kathleen, D. Jean, and P. Charles, "Sleep actigraphy," Journal of Sports Sciences, March, vol. 30(6), pp. 541545, 2012.

[10] C. Gabriel, H. Muana, A. Hítalo, M. Valéria, A. Wbinayara, C. Ana, and C. Rodrigo, "Sleep Quality And Its Association With Psychological 316-32, 2017.

[11] F. Yaqoot, A. Suhail, M. Jake and A. Abdullah, "Exploring Gender Difference in Sleep Quality of Young Adults: Findings from a Large Population Stud," Clinical Medicine \& Research, Volume 14, Number 3-4, 138-144, 2016.

[12] P. Astrand, and K. Rodahl, "Textbook of Work Physiology," New York: McGraw-Hill Book Company, 1977.

[13] D. Erlacher, E. Felix, A. Olufemi, and G. Hamdi, "Sleep habits in German athletes before important competitions or games. Journal of Sports Sciences, May, vol. 29(8), pp. 859-866, 2011.

[14] T. Anderson, and L. Wideman, "Exercise and the cortisol awakening response: a systematic review," Sports medicine-open, vol. 3(1):37, 2017.

[15] S. Assari, M. Maryam, C. Caldwell, and M. Zimmerman, "Anxiety Symptoms During Adolescence Predicts Salivary Cortisol in Early Adulthood Among Blacks; Sex differences," Int J Endocrinol Metab. October, vol. 13(4), e18041, 2015.

[16] Chrousos, A. Vgontzas, and K. Ilia, "HPA Axis and Sleep," NCBI Bookshelf. A service of the National Library of Medicine, National Institutes of Health. Last update January 18, 2016.

[17] A. Stijn, C. Jean, B. Nabilah, and W. Michael, "Poor habitual sleep efficiency is associated with increased cardiovascular and cortisol stress reactivity in men," Psychoneuroendocrinology vol. 81, pp. 151-156, 2017.

[18] D. Michael, and S. Thomas, "The Neurobiology of Sleep and Wakefulness," Psychiatr Clin N Am, 2015. duration and quality in elite athletes measured using wristwatch Symptoms In Adolescent Athletes," Rev Paul Pediatr. Vol. 35(3), pp. 